\title{
Criteria and specifications of physical degradation of arable soils (offers on perfecting normative basis)
}

\author{
V. Medvedev, \\ Academician of the NAAS, Doctor of Biological Sciences \\ I. Plisko, \\ Candidate of Agricultural Sciences \\ National Scientific Center «Institute of Soil Science and Agrochemistry named after O.N. \\ Sokolovsky»
}

The purpose. To specify criteria and specifications of physical degradation of soils, to develop offers to perfecting normative basis. Methods. Analytical, comparative, statistical, Results. Conceptual approaches to searching criteria of physical degradation are justified. On the basis of comparative long study of virgin soil (long fallows) and arable soils some criteria are offered which can be used for diagnostics of physical degradation. The survey of quantitative and quality criteria of physical degradation of arable soils is realized. Assessment is made of propensity of soils to physical degradation and speed (intensity) of development of degradation processes on concrete instances. Diagnostic parameters are specified and preliminary specifications of physical degradation of arable soils are determined. Conclusions. On the basis of own researches and literary data some offers are made (for discussion and refinement) about the list of indexes and specifications of physical degradation of arable soils.

Key words: physical degradation, arable soils, criteria, parameters, specifications.

Introduction. Due to the Hooke's law [1], soil responds to mechanical load - inflicted soil - deformation in different manners. Under insignificant loading, soil does not respond at all. This is the so-called inert phase. Along with increase of loading intensity, the soil responce becomes ever more indicative, whereby the soil is actively load - resisting and eventually, recovering rather soon to its original state. This is the relaxation phase. With further increase of loading on soil, there occur ever deeper and longer timeconsuming processes. At this stage (the elasticity), soil - resistanceability to loading is mostly exhausted; yet after several years of no-load conditions, the soil is capable of recovering back to its initial shape. And the last stage is plasticity. The soil body undergoes an irreversible spoil, thus actually turning up into a worst class - formation. The soil responce to the loading does not depend on the soil - type; whereas, with gradual increase of loading index, the soil resistance falls down adequately, thus ending up with irreversible soil- transformations. In this very manner as with physical deformation, soils are also subject to salinization, oxidation and contamination.

Using the laws of soil deformation under physical loading, one can readily determine conditions whereby soil either remains stabile or becomes degraded. Conditions of soil - degradation occurrence: wherever loading value exceeds the soil -stability index. Conditions of soil - stability: wherever a loading value is below the stability index, whereas the load - normative must be either lower or equal to elasticity indicator. Quantitative indices which correspond to inertness, relaxation, elasticity or plasticity states, can be determined via special (laboratory or native) regimel experiments. The purpose of such test-trials is to identify values of certain loading that would lead to irreversible soil transformations. Loading of any degree below a predetermined critical point causes no soil - degradation. However, any loading above the critical level shall initiate deformation.

In the course of soil-density growth (and depending also on soil-humidity conditions), there exist certain values of loading pressure, whereafter soil undergoes a gradual dis-compaction (if any at all). This 
is why values of structure-equilibrium density of historically long- plown soils tend to increase, whereas the increased structural density of arable-layer substratum remains stabile for decades [2].

Objectives of the study: To specify criteria and normatives for physical soils' degradation assessment, and elaborate proposals to upgrade relevant soil- normative- regulatory framework.

Research methodology: comparative, analytical, field-test, regimel, statistical and mathematical methods and techniques.

Results of the study: Owing to long-term comparative studies for virgin and arable soils, certain criteria (being perspectively viable for diagnosis of physical soil-degradation phenomena) have been proposed. Gradual transformation of structural units and pore space (due to transition from isotropic structure to anisotropic one), occurs by the following scenario:

- in the course of long- term impact by agri-tillage machinery on soil, - size, shape and pore space of soil-aggregates undergo definite changes;

- whereas virgin soils are mostly characterized by isotropic or approximate structure (while soilproperties do not almost depend on vectoral direction), tilled soils are typical, on the contrary, with their anisotropic structure whose properties vary in dependence on a direction-vector selected. Structural anisotropy is specified by the soil- structure- lumps' size anisotropy;

- drag of aggregation processes accompanied by accumulation of heavy soil-clods, decrease in percentage of agronomically useful structure, deterioration of soil water resistance and mechanical strength;

- after a long plowing history, the soil- structurality coefficient calculated per ratio of: [10 to 0,25 $\mathrm{mm}$ - sized aggregates] vs [bulk of dusty and cloddy structures], reveals fall-down of structurality-index by 1.6 to 2.9 times;

- amount of agronomically usable-sized aggregates in arable soils (along with their water resistance) is decreasing, as compared to virgin land;

- a dramatic decrease of arable soil- aggregates' water resistance is its typical feature, whereby water resistant $>3 \mathrm{~mm}$ aggregates are practically vanishing;

- this is, obviously, a consequence of organic matter loss along with accelerated organics mobility;

- intensities of mechanical destruction of soil-aggregates in virgin and arable land- samples are different;

- under artificial conditions of soil-samples' comminution-screening by rotational vibro-mill test, virgin-soil aggregates lost their integrity so slowly that after an hour of the trial, they were destructurized but insufficiently;

- arable-soil aggregates collapsed generally fast from the very start, yet here and there their destruction lasted throughout the entire soil- grain sifting procedure;

- decrease of humus- and calcium - content in arable soils hinders inevitably the soil - particles' aggregation processes;

- soil- structure compaction results in steady rise of equilibrium soil- density and origin of consolidated aggregates, alongside decrease of aggregate inter-pore dimensions. Due to disobedience of standard norms of permissible soil-tillage machinery load (exaggerated by its uncontrolled traffic across the crop-fields), equilibrium density of soil-structure within roots' bearing layer of arable chernozems is notably exceeding that in natural-intact conditions. The plastic deformation promotes aggregates' consolidation, resulting in their density growth alongside intragranular porosity decrease. As a result, conditions of plants' water-mineral nutrition deteriorate also. Due to excessive heavy tractors' employment in spring season, the sub-seed layer tends clearly to compaction, whereas the arable-layer substratum across large areas of Ukrainian cultivated lands is already overcompacted. After decades-long soil-tillage history, the plown substratum density can exceed 35 to $40 \mathrm{kgf} / \mathrm{cm}^{\prime}$, thus limiting significantly the depth of plants' roots zone; 
- deterioration of agronomically important morphological features of crop-roots, roots' permeability through soil -aggregates, and plants' bioproductivity. In degraded soils with an overcompacted substratum within roots' bearing layer, depth of root-system penetration, quantity, roots' branching pattern and the roots-productivity index decrease. These factors reduce plants' adaptation to adverse conditions, especially at water/ moisture deficiency in soil;

- an expansion of soil cover heterogeneity well manifested at formation of specific horizontal and vertical profiles. On the contrast to virging land, the long- term plown fields' cultivation results in expansion of soils' time- and space- related heterogeneities. According to Great Britains' 150 years experience, fertilizers application not only fails to eliminate the nutritional regime's spatial heterogeneity in soil, but tends to amplify it. Natural relaxation processes, as well as gleyification, lessivage and podzolization, also contribute to the soil- structure heterogeneity. Now, the expansion of arable soils' heterogeneity is ever more actualizing the precise agriculture spreadout challenge;

- occurrence of preferential down- and upward moisture flows. Preferential moisture-flows (or deepsoil filtration through large pores) originate in old-plown soils due to presence of cloddy fractions and cracks therein. It is the very soil-structure clods and cracks that conduct airprecipitation moisture down the soil-profile. A relevant exponential link (i.e. a repeated boom of filtration intensity with every new occurrence of certain amount of soil- clods) has been confirmed. It was well proven that upward moisture flows may belong to preferential flows, resulting in non-productive losses of productive moisture - as a result of physical evaporation processes. Thus, after long history of mechanical soil tillage and almost inevitable soil destructuruzation processes, soil- water regime undergoes downgrade under effect of downward and upward water flows;

- distinctly expressed relaxation processes accompanied by properties' and regime - changefluctuations between soil-tillage stage and quasi-equilibrium status formation. Virgin soils have almost no peculiar fluctuations in change of their main structural components, where after the cultivation stage, the soil air-capacity would largely increase or the solid phase per unit volume would reduce; to be followed (due to relaxation) by equilibrium density-recovery to a higher degree than before. Hence, all other processes functionally related to the soil structural density, feature the same fluctuating nature. Therefore, arable chernozem is markedly different from virgin soil physical parameters. Among other criteria important for the degradation process and degraded soils characterization, authors note the following.

Recoverability and irreversibility of soils. Recoverability is the property of soil to restore its most typical (under given local conditions) parameters, after a mechanical or other loading factor is eliminated. There is reason to believe that the old-plown soil has lost its recoverability because new parameters have become stable. In fact, the old-plown soil has acquired another morphological profile, alongside other properties and regimes. New features must be called 'quasi-stable'; since, provided if an arable plot is withdrawn from its plowing agenda and sublected to renaturalization for a fairly long period of time, its properties shall be recovered. These assumptions are evidenced by the $25-\mathrm{yr}$ studies for properties of chernozem soils under lealand conditions [3]. In favor of this idea evidence soil observations conducted under zero-tillage regime within the same time- period. Thus renovated old-plown soils have practically no active erosion indications nor any other signs of degradation.

Hence, it is so important that old-plown soils that have acquired clear signs of degradation along with loss of their economic value, be withdrawn from regular arable lands' register. This action promises an extremely important step towards improving the status of soils and environment.

Propensity for physical degradation (e.g., compaction). Results of studies with samples of chernozem typical heavy-loamy, chernozem southern light-clayey and soddy-podzolic sandy soil are shown in Figure. 


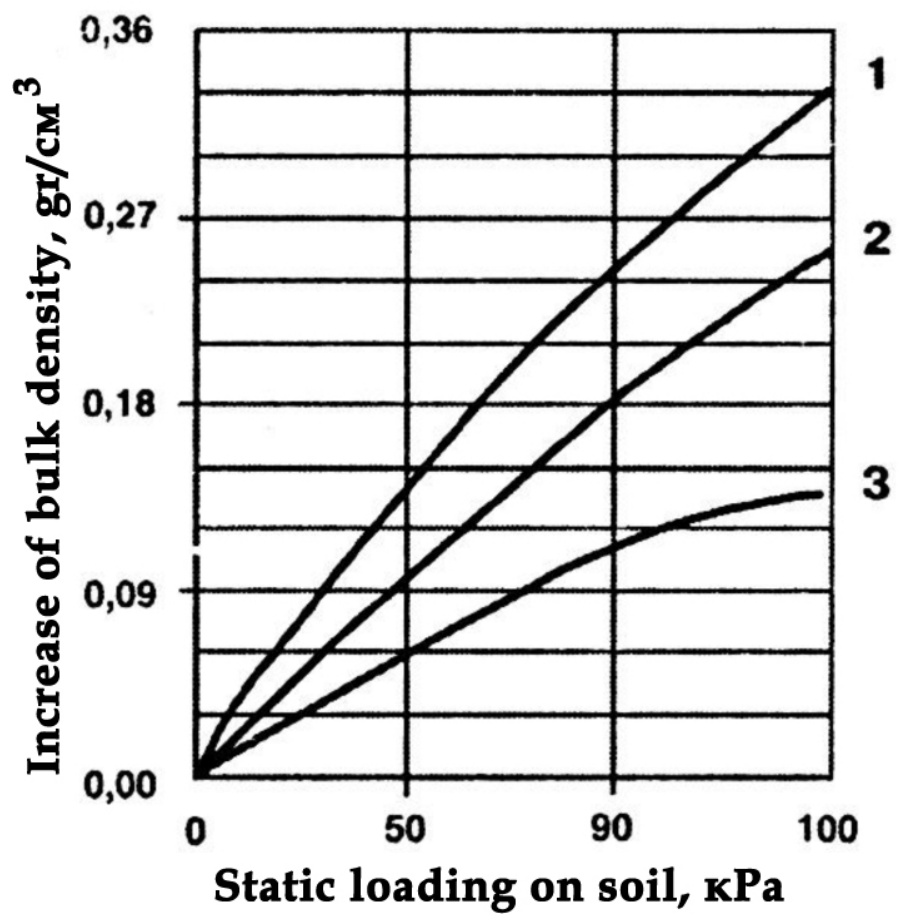

Soil susceptibility to compaction in dependence on static loading on chernozem typical heavy-loamy (1), chernozem southern light-clayey (2) and soddy- podzolic sandy soil (3). Left upright: "Increase of structural density, $\mathrm{g} / \mathrm{cm}^{\text {"'; }}$ horizontal line: "Static koad on soil, $\mathrm{kPa}$ ".

Figure. Deformation of thus investigated soils is described by exponential dependencies.

Yet, while the curve of the soddy-podzolic soil of light particle size distribution tends to decline to horizontal characteristic after moderately increased density, the density- curve of shernozem typical heavy-loamy continues to rise proportionally with further increase in loading, that is, mechanical stability of the light granulometric composition soil is of significantly higher value. This kind of dependence shows the chernozem disability to withstand even a relatively low loading. Scholar Igor A. Krupenikov (the worldrecognized black soils' explorer) used often to note that ..."Chernozem is a unique phenomenon that unites such opposite features as vigour and defencelessness" [4].

Dependencies are described by the following equations for:

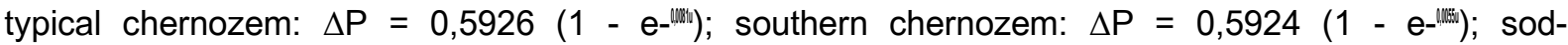
podzolic soils: $\Delta P=0,1958$ (1-e-"watu),

where: $[u]$ is parameter of exponential dependence at determining an increase of the soil structure density; $[\Delta P]$ - increase in the the structure density, $\mathrm{g} / \mathrm{cm} ;$; and $[\chi]$ is static loading on soil, $\mathrm{kPa}$.

The $[u]$ parameter is defined as follows:

$\mathrm{u}-105.56-\sqrt{ } 11142-111,11 \chi$ at $\chi<100 ; \mathrm{u}=\chi$ at $\chi \geq 100$.

Under real conditions, the tendency of soil to degrade (regarding the compaction parameter) may vary depending on such many factors as: status of soil-cover (freshly plown or vegetation-topped); moisture; method and depth of the previous soil-tillage; type ${ }^{\mathrm{TM}}$ and weight of the field machinery unit used.

Most of these factors were studied but insufficiently; especially cases of long-trem soil-loading pressure conditions.

Threats of degradation occurrence. Authors of this paper derived quantitative indicators of degradation. Negative nature-caused phenomena with arable land, and degree of expansion of thus affected arable areas from previous studies and bibliography sources, as well as calculated with use of digitized maps [5].

Areas where degradation phenomena could occur (regarding their dynamic indices (e.g., compaction) were calculated per their indications in equilibrium status; amount of soil-clods and soil-dust after presowing tillage in spring and basic plow- cultivation in autumn periods. 
Threat of crop-productive water-deficit is determined by aid of agro-climatic bibliography references, while values of specific resistance are calculated via measurements of normative items (Table- 1).

1: Areas of degradation phenomena spreadout across the Ukraine, in terms of their threats/ negative tendencies for national arable soils (a sample)

\begin{tabular}{|c|c|c|c|}
\hline \multirow[b]{2}{*}{$\begin{array}{l}\text { Index of soil-degradation or } \\
\text { negative soil-properties }\end{array}$} & \multirow[b]{2}{*}{ Quantitative characteristics } & \multicolumn{2}{|c|}{ Areal of spreadout } \\
\hline & & Mio ha & $\begin{array}{l}\text { Percent of } \\
\text { arable } \\
\text { areal }\end{array}$ \\
\hline \multicolumn{4}{|l|}{ Threats: } \\
\hline soil- clod formation & $\begin{array}{l}\text { over } 10 \% \text { of }>10 \mathrm{~mm} \text {-sized lumps in } \\
\text { arable layer }\end{array}$ & 3,8 & 12,1 \\
\hline soil-dusting & over $10 \%$ of $<0,25 \mathrm{~mm}$ fractions & 14,1 & 44,1 \\
\hline soil abrasion & plowshare triggering $>70 \mathrm{~g} / \mathrm{ha}$ & 6,9 & 21,6 \\
\hline soil compaction & $>1,25 \mathrm{~g} / \mathrm{sm}^{\prime}$ in arable layer & 17,3 & 54,1 \\
\hline soil dispersion & over $8 \%$ by the factor of Kachyns'kyy & 5,8 & 18,1 \\
\hline $\begin{array}{l}\text { deficit of productive moisture in } \\
\text { the spring } \\
\text { deficit of productive moisture }\end{array}$ & $<20 \mathrm{~mm}$ in a layer $0-20 \mathrm{~cm}$ & 6,9 & 21,6 \\
\hline $\begin{array}{l}\text { during the formation of } \\
\text { generative organs }\end{array}$ & $<100 \mathrm{~mm}$ in a layer $0-100 \mathrm{~cm}$ & 21,3 & 66,6 \\
\hline $\begin{array}{l}\text { probability of deviation of soil } \\
\text { moisture from physical maturity }\end{array}$ & $\begin{array}{l}\text { over } 22 \% \text { and less } 13 \% \text { in arable layer in } \\
\text { spring }\end{array}$ & 9,5 & 29,7 \\
\hline $\begin{array}{l}\text { reduced amount of days with } \\
\text { humidity of the optimal } \\
\text { crumbling, in the spring }\end{array}$ & $<5$ & 1,5 & 0,05 \\
\hline similarly, in autumn & $<5$ & 11,0 & 34,3 \\
\hline $\begin{array}{l}\text { ultra high of soil resistance for } \\
\text { plowing }\end{array}$ & $>0,6 \mathrm{kgf} / \mathrm{sm}^{2}$ & 9,1 & 28,4 \\
\hline $\begin{array}{llr}\text { reduced } & \text { quantity } & \text { of } \\
\text { agronomically } & \text { valuable } & \text { soil } \\
\text { aggregates } & & \end{array}$ & less $50 \% 10-0,25 \mathrm{~mm}$-sized aggregates & 14,1 & 44,1 \\
\hline $\begin{array}{l}\text { reduced soil water-stable of } \\
\text { aggregates }\end{array}$ & less $40 \%>0,25 \mathrm{~mm}$--sized aggregates & 8,4 & 26,2 \\
\hline $\begin{array}{l}\text { reduced of soil total equilibrium } \\
\text { porosity }\end{array}$ & less $50 \%$ in arable layer & 11,1 & 34,7 \\
\hline
\end{tabular}

During the follow-on research period, areas of negative events listed in the above Table (with their geographical delineation) shall be clarified with purpose to use them at regionalization of anti-degradation activities.

Speed (intensity) of degradation processes. Information on rates of physical degradation spreadout is extremely poor.

This can be explained by almost absolute absence of long-term observations on change of arable soil conditions under impact by agricultural activities.According to authors' observations, the equilibrium density parameter tends to increase. We recognized this trend while exploring virgin lands of southern chernozem at "Askania-Nova" Reservation Park (Kherson region) in comparison with soil of a nearby testplot being plown for over 100 past years. Soil-density parameter had been measured twice a midsummer session in 1967, 1982 and 1997 (totally, in 6-time repetitions throughout 15-yr intervals). After 30 years of the srudy, values of the virgin soil-density turned out to remain unchanged. 
Within plown $60-80 \mathrm{~cm}$ deep soil, values of soil density are likely to be somewhat higher, with up to 0.3 $\mathrm{g} / \mathrm{cm}^{3}$ error- tolerance for top layer. Within arable layer, the equilibrium density elevated rapidly in several years; whereas in depth, it spread out gradually at a rate of $\sim 0.6 \mathrm{~cm} / \mathrm{yr}$. These data require verification which is only possible in availability of several simultaneous equidistant surveys (i.e., centralized monitoring for physical status of soils). Range of soil-degradation occurrencies is shown in Tables 2 and 3.

Thus, quantitative criteria for assessment of arable soils physical degradation include: partial loss of agronomically usable structure, water-resistance and mechanical strength; soil-dust losses that conflict with soil-aggregation processes; growth of equilibrium soil density and hardness; (iv) decrease in power of the root-bearing layer and deteriorated pore-permeabilityorrosion resistance; deterioration of biota activity.

2. Degrees of soil degradation in terms of soil structurality and soil structural density (conferred from indices of medium- and heavy- soils' particle-size composition)

\begin{tabular}{|c|c|c|c|c|}
\hline \multirow{2}{*}{ Indicators } & \multirow{2}{*}{ Intact soil } & \multicolumn{3}{|c|}{ Degree of soil- degradation } \\
\hline & & low & medium & high \\
\hline \multicolumn{5}{|l|}{ Structurally-aggregate composition: } \\
\hline $\begin{array}{l}\text { - content of dry- air } 10-0.25 \mathrm{~mm} \\
\text { aggregates, per cent }\end{array}$ & $>70$ & $60-70$ & $40-60$ & $<40$ \\
\hline $\begin{array}{l}\text { - content of water resistance- } \\
\text { >0.25 mm aggregates, per cent }\end{array}$ & $>45$ & $35-45$ & $25-35$ & $<25$ \\
\hline \multicolumn{5}{|l|}{ Equilibrium density, $\mathrm{g} / \mathrm{cm}^{3}$ : } \\
\hline - heawy soils & $<1.3$ & 1.3 & 1.4 & $>1.6$ \\
\hline - light soils & $<1.3$ & 1.3 & 1.5 & $>1.6$ \\
\hline
\end{tabular}

\section{Assessing the degrees of soil degradation [6]}

\begin{tabular}{|c|c|c|c|c|c|}
\hline \multirow{2}{*}{ Indicators } & \multicolumn{5}{|c|}{ Degree of soil- degradation } \\
\hline & $n / a$ & low & medium & high & dramatic \\
\hline \multirow{2}{*}{$\begin{array}{l}\text { Equilibrium soil-structure density, } \\
\text { per cent }{ }^{(1)}\end{array}$} & $<$ & $10-$ & \multirow{2}{*}{$21-30$} & $31-$ & \multirow{2}{*}{$>40$} \\
\hline & 10 & 20 & & 40 & \\
\hline \multirow{2}{*}{$\begin{array}{l}\text { Soil- structure composition (i.e. content of } 0.25 \text { - } \\
10.0 \mathrm{~mm} \text { air-dry aggregates in arable layer, \% }\end{array}$} & $<$ & $15-$ & \multirow{2}{*}{$26-35$} & $36-$ & \multirow{2}{*}{$>45$} \\
\hline & 15 & 25 & & 45 & \\
\hline Content of $>0.25 \mathrm{~mm}$ water resistan & $<$ & $10-$ & $21-30$ & $31-$ & $>40$ \\
\hline aggregates , per cent ${ }^{(2)}$ & 10 & 20 & & 40 & \\
\hline
\end{tabular}

Qualitative criteria include: more frequent occurrence of soil-clods, crust and arable substratum; dynamics of structure, properties and regimes, as well as contrast-range and deficit of air-water regime; change in the ratio of inter- and intra-aggregate pores during the crop-growing season; heterogenetization and elevation of anisotropy; occurrence of specific horizontal and vertical profiles; dominance of preferential down- and up-ward moisture flows.

Diagnostic parameters and previous normatives. Table 4 shows the preliminary normatives of arable soils degradation assessment conferred from authors' research and bibliography sources [7-10]. Said normatives are proposed here to further discussion and reasoning.

\section{Criteria and Parameters of soil physical degradation ploughed up}

\begin{tabular}{|l|l|l|}
\hline Criteria & Parameters & $\begin{array}{l}\text { preliminary } \\
\text { specifica-tions }\end{array}$ \\
\hline $\begin{array}{l}\text { Lowering of structure (for } \\
\text { soil loamy and clay texture) }\end{array}$ & Factor of dispersivity & $8-10$ and above \\
\hline
\end{tabular}




\begin{tabular}{|c|c|c|}
\hline & $\begin{array}{l}\text { Clodyness: } \\
\text { By quantity aggregates }>10 \mathrm{~mm} \text { after a prime plow, } \% \\
\text { Too most after and before sowing, } \% \\
\text { quantity aggregates } 10-0,25 \mathrm{~mm}, \% \\
\text { By quantity aggregates }<0,25 \mathrm{~mm} \text { (silt) under sowing, } \% \\
\text { By waterstable, } \% \\
\text { On waterstable koeficient }{ }^{2} \\
\text { On waterpenetration, } \mathrm{mm} / \text { hour. }^{3} \\
\text { On koef of lowering waterpenetration }\end{array}$ & $\begin{array}{l}30 \\
>10 \\
<40 \\
>20 \\
<30 \\
<0,4 \\
<30 \\
>4,0\end{array}$ \\
\hline overcompaction & $\begin{array}{l}\text { Equilibrium bulk density of arable layer, } \mathrm{gr} / \mathrm{CM}^{3} \text { for soil: } \\
\text { heavy } \\
\text { ligth } \\
\text { Bulr density in sole soil fof soil: } \\
\text { heavy } \\
\text { ligth } \\
\text { Bulk density in under seed layer for soil: } \\
\text { heavy } \\
\text { ligth }\end{array}$ & $\begin{array}{l}1,4 \\
1,7 \\
1,4 \\
1,7 \\
1,2 \\
1,5\end{array}$ \\
\hline Microfabric & $\begin{array}{l}\text { Koef of form aggregates } \\
\text { Ordering of aggregates } \\
\text { Parity ekstra-and intramodular pores } \\
\text { The maintenance }\{\text { contents }\} \text { in pores of not aggregated material, } \\
\%<0,25\end{array}$ & $\begin{array}{l}<0,25 \\
<3 \\
>1,8 \\
>30\end{array}$ \\
\hline Index of physical condition & Koef & $<0,7$ \\
\hline \multicolumn{3}{|c|}{$\begin{array}{l}\text { - } 1 \text { - pays off on a parity of silt texture and microaggregates analyses; } 2 \text { - on a parity\{ratio\} of structural } \\
\text { fractions in the size }>0,25 \mathrm{~mm} \text { at wet and dry sifting; } 3 \text { on average waterpenetration, certain during not less } 6 \\
\text { hour supervision; } 4 \text { - on factor Ueidella-Kuharenko; } 5 \text { - it is certain by a micromorphological method by } \\
\text { quantity\{amount\} of grains less than } 50 \mathrm{m \kappa} ; 6 \text { - on a geometrical average difference optimal fnd real } \\
\text { parameters physical properties }\end{array}$} \\
\hline
\end{tabular}

\section{Findings}

A review of quantity \& quality criteria of arable soils' physical degradation has been implemented. Among the quantitative criteria: partial loss of agronomically useful structure; water resistance and mechanical strength; soil-dusting loss; growth of equilibrium density and hardness etc were identified.Among the qualitative criteria: strengthening of the dynamism of the structure, properties and modes, the contrast and deficit of the air-water regime, heterogenetization and enhancement of anisotropy, the emergence of specific horizontal and vertical profiles, the dominance of preferential downward and upward flow of moisture. Using the patterns of soil deformation under the action of the load (inertia, relaxation, elasticity and plasticity), the conditions under which the soil remains stable or degraded is determined. Conditions of degradation: load exceeds stability. Stability: Load is less stable, and its standard must be less than or equal to elasticity. On the basis of own research and literary data, suggestions (for discussion and clarification) concerning the list of indices and norms of physical degradation of arable soils are included.

\section{References}

1. Sergeev E.M. // Soil Science // 4th revised edition, Moscow State University, 1973. - 387 pp. 
2. Scharatt D.C. // Amelioration of soil compaction by freezing and thawing // Proc. of Int. Sym Fairlaks Hanover - 1997.-No. 10. - PP. 182 - 188.

3. Medvedev V.V. // Structure of soil (methods, genesis, classification, evolution, geography, monitoring, protection) // Kharkiv, 13th Printing House, 2008. - 406 pp.

4. Krupenikov I. A. // Chernozem - Our Wealth // Chisinau: Cartia Moldoveniasche, 1978. - 106 pp.

5. T. N. Laktionova, V. V. Medvedev, K. V. Savchenko et.al. // Database "Soil Properties of Ukraine". Structure and Usage // - 2nd edition; Kharkiv, №1, 2012. - 150 pp.

6. Soil protection. Soil degradation Assessment of chemical and physical degradation of soils //National Standard of Ukraine DSTU7872: 2015// State Enterprise "UKRNDNTS", 2016. - 5 pp.

7. Sheyin E.V. //Course of Soil Physics: Textbook // Moscow: MSU, 2005. - 432 pp.

8. Dolgov S.I., Bakhtin P.U. // Scale for assessing the readiness of the soils for sowing due to its structural state // Agrophysical Methods of Soil Research. - Moscow: Nauka, 1966. - 67 pp.

9. Kuznetsova I.V. // About certain criteria of evaluation of physical properties of soils // Soil science Journal \#3, 1979, 81- 88 pp.

10. Nikolaeva S.A., Plotnikova T.A. //Degradation areas of transformation of steppe zone chernozems at irrigation // Degradation and protection of soils. - Moscow: Nauka, 2002. - 513-550 pp. 